\title{
Ronald Barnett, Beyond All Reason: Living with Ideology in the University
}

Manuela Guilherme

\section{OpenEdition}

Edição electrónica

URL: http://journals.openedition.org/rccs/1165

DOI: $10.4000 /$ rccs. 1165

ISSN: 2182-7435

Editora

Centro de Estudos Sociais da Universidade de Coimbra

\section{Edição impressa}

Data de publição: 1 outubro 2003

Paginação: 184-187

ISSN: 0254-1106

\section{Refêrencia eletrónica}

Manuela Guilherme, "Ronald Barnett, Beyond All Reason: Living with Ideology in the University », Revista Critica de Ciências Sociais [Online], 66 | 2003, posto online no dia 01 outubro 2012, consultado o 22 setembro 2020. URL : http://journals.openedition.org/rccs/1165; DOI : https://doi.org/10.4000/rccs. 1165 


\section{Recensões}

\section{Seixas, Ana Maria, Políticas Educativas e Ensino Superior em Portugal: $A$ inevitável presença do Estado. Coimbra: Quarteto Editora, 2003, 248 pp.}

A obra Políticas Educativas e Ensino Superior em Portugal publicada por Ana Maria Seixas centra-se na análise das várias tentativas de reforma do ensino superior desde os anos 70 até à actualidade, tendo em conta o contexto de criação de um espaço europeu de ensino superior.

O livro presta um importante contributo ao conhecimento do sistema educativo português, nomeadamente pela sistematização de informação e análise do processo de expansão do ensino superior, bem como das alterações ocorridas no papel regulador do Estado. A este respeito, uma questão central que merece a atenção da autora é a da autonomia institucional, que é abordada em articulação com as temáticas da avaliação e funcionamento. Estes assuntos são tratados no quadro das mutações recentes neste nível de ensino e tendo em conta as implicações da introdução de uma política neoliberal e/ou a redefinição do papel do Estado.

O estudo desenrola-se em quatro capítulos. No primeiro, procura-se abordar o impacto do processo de globalização económica nos sistemas de ensino superior e as transformações do papel do Estado, traduzidas na emergência do "Estado avaliador", apresentando-se também as principais orientações do Banco Mundial, da OCDE e da Unesco. Esta reorientação da aç̧ão estatal expressa-se numa articulação cada vez mais forte entre os sistemas educativo e produtivo e na separação entre o Estado e a educação. A autora constata que os desempenhos das diferentes instituições, embora encobertos por uma retórica de eficiência, qualidade e responsabilidade, revelam que o Estado tende cada vez mais a circunscrever-se a um estatuto de mero avaliador.

No segundo capítulo pretende-se retratar o processo de expansão e diversificação do sistema de ensino superior em Portugal a partir da década de $60^{1}$, considerando-se que este passou por várias fases e modelos. Um primeiro modelo, com Veiga Simão, que se caracterizou pela distinção entre o ensino superior universitário e não universitário. Um segundo modelo caracterizado pela tentativa de expansão do ensino superior através da generalização dos cursos de curta duração, onde todos os estabelecimentos de ensino tinham o mesmo estatuto e concediam os mesmos graus. E por fim, um terceiro modelo que passou pela introdução de uma lógica binária, Universidades versus Politécnicos. Para além de descrever este processo de expansão, a autora propõe várias pistas de explicação, entre as quais, o aumento da procura, fomentada pelas crescentes exigências de qualificações do mundo do trabalho, o progresso tecnológico e a crescente competição entre grupos sociais pela posse de credenciais escolares, socialmente associadas a posições de status desejáveis.

O terceiro capítulo analisa exclusivamente a evolução do ensino privado em Portugal, onde são apresentados diferentes ti-

\footnotetext{
${ }^{1}$ Foi exactamente a partir desta data que o ensino superior português registou um período de forte crescimento que se prolongou até à década de 70 , assistindo-se depois a um período (anos 80) de estabilização ou até mesmo de decréscimo do número de estudantes, que voltou a aumentar após 1988. Mas, a partir de 1995 assiste-se a uma diminuição do número de candidatos, atingindo sobretudo o ensino superior privado.
} 
pos de instituições dentro do sector privado, realçando a complexidade e ambiguidade na dicotomia público/privado, e concluindo a autora que se evoluiu de um sector periférico para um sector de massas. A partir da análise das imagens veiculadas pelos discursos relativos ao ensino superior privado, distinguem-se, por um lado, os aspectos consensuais e, por outro, as divergências. No seio destas contradições continua a ser central a análise da relação entre o Estado e a sociedade portuguesa. Um outro aspecto importante tratado neste capítulo refere-se à questão da política de privatização do ensino superior, uma vez que se assiste à sua crescente importância, devido ao aumento da procura de ensino superior e à estagnação ou até mesmo declínio dos orçamentos públicos para a educação. São referidos a este propósito alguns dos discursos mais críticos que acentuam a ausência de qualidade do sector privado, a qual terá um impacto negativo no conjunto do ensino superior.

Uma das contradições que a autora dá conta é a seguinte: enquanto as instituições orientadas para o mercado são pressionadas para atenuar a sua concepção empresarial de ensino e desenvolverem uma maior orientação para o conhecimento e a produção científica, as instituições estatais, por seu lado, são incentivadas a aumentar a sua capacidade de autofinanciamento, a racionalizarem as suas estruturas e práticas de gestão, mudando a sua cultura organizacional, para responderem de forma mais adequada às necessidades do meio que as rodeia. Para a autora, esta atitude expressa bem a ideia de que a introdução da lógica de mercado e de privatização como forma de regulação do ensino superior, não tem tanto a ver com as próprias virtudes do mercado ou do ensino privado, mas sim com questões pragmáticas de gestão de um sistema que exige cada vez mais recursos, e cuja legitimidade é cada vez mais posta em causa.
Por fim, no último capítulo, são abordadas as principais alterações nos restantes instrumentos políticos de governo, ou seja, a autonomia, o financiamento e a avaliação. Refere-se a questão do financiamento e dos cortes orçamentais, que não é um problema exclusivo das instituições de ensino superior portuguesas, e consideram-se o discurso da qualidade e da competitividade como principais factores de justificação para a obtenção de receitas próprias, nomeadamente através da cobrança de propinas.

A autora conclui afirmando que a organização da oferta da educação durante as décadas de 80 e 90 se caracterizou pela diminuição da importância quantitativa da intervenção do Estado e pelo facto do princípio do mercado, associado à metáfora da livre escolha, se ter instituído simbolicamente como uma lógica de funcionamento desejável dos sistemas educativos. Ao longo deste período assistiu-se, no campo do ensino superior, à introdução de uma retórica de mercado que colide com o modelo de Universidade orientada pelo e para o conhecimento, e a uma redefinição do papel do Estado, associada à ideia de privatização e "empresarialização" da educação.

Apoiada numa exaustiva sistematização de informação, esta obra fornece as bases para diagnosticar o estado da arte no sistema de ensino superior em Portugal. Todavia, e principalmente atendendo a que muitas das questões aqui abordadas têm sido objecto de recorrentes polémicas e disputas políticas marcantes nos últimos anos, esperar-se-ia que a autora avançasse um pouco mais no aprofundamento da análise, quer no plano das causas estruturais e sociológicas, quer sobretudo posicionando-se quanto às múltiplas opções que estão aqui em confronto.

Teresa Maneca Lima 


\section{Manuela Guilherme, Critical Citizens for an Intercultural World: Foreign Language Education as Cultural Politics. Clevedon / Buffalo: Multilin- gual Matters, 2002, 312 pp. (colecção Languages for Intercultural Commu- nication and Education, dir. M. Byram e A. Phipps)}

Critical Citizens for an Intercultural World: Foreign Language Education as Cultural Politics é de leitura obrigatória para educadores, legisladores e investigadores dispostos a mergulhar nas complexidades do ensino/aprendizagem das línguas/culturas estrangeiras, considerado como um campo de estudo de natureza social e política. A hipótese subjacente, tal como é salientado por Duarte Silva no prefácio do livro (ix), é que "a consciência cultural crítica é um objectivo muito desejável no ensino/ aprendizagem de línguas estrangeiras e os seus programas devem adoptar uma dimensão crítica tanto nos seus conteúdos como nas práticas docentes" e que esta perspectiva "desafia qualquer professor de língua/cultura estrangeira a desempenhar um papel mais pró-activo na preparação de cidadãos criticamente conscientes e reflexivos". O ponto de partida da autora é, portanto, o conceito de educação como sendo o instrumento social mais eficaz para promover a mudança e o progresso.

Os fundamentos teóricos da Pedagogia Crítica são explorados ao longo dos dois primeiros capítulos, nos quais se vão citando teóricos tais como Freire, Giroux, Habermas, Horkheimer, Adorno e Marcuse. O impressionante aparato teórico e bibliográfico patente em todo o livro está bem reforçado nestes capítulos.

$\mathrm{O}$ argumento sólido do primeiro capítulo revela a ligação entre a Pedagogia Crítica e, simultaneamente, a Política Cultural e o Ensino/Aprendizagem de Línguas Estrangeiras. O leitor é convidado a reflectir sobre a natureza política do processo educativo e sobre o papel desempenhado pelas escolas enquanto instituições dirigidas para a preparação de cidadãos críticos e activos. A Pedagogia Crítica é apresentada como sendo a base para o desenvolvimento de um novo modelo de educador, o de um "intelectual transformador" (22). Este modelo tem raízes em teorias - Teoria Crítica, Pós-modernismo, Estudos Culturais, Progressivismo e Reconstrutivismo das quais retira conceitos tais como a preocupação da emancipação, a reafirmação da diferença, a necessidade de transgredir fronteiras, a busca da democracia e a educação para a cidadania. A pedras de toque da Pedagogia Crítica são aqui identificadas como sendo a necessidade de privilegiar a dissenção como força motora da democracia, a diferença versus a homogeneidade num mundo globalizado, o diálogo entendido como a "ponte entre a reflexão e a acção" (48), o exercício do poder como uma possibilidade à mão de qualquer cidadão, a relevância de se adoptar uma atitude pró-activa e, finalmente, a ênfase numa pedagogia da esperança, do "ainda não”. Isto apesar de a Pedagogia Crítica ter recebido algumas críticas, tal como o texto refere, sendo a sua maior insuficiência precisamente a falta de adesão por parte dos educadores. É nesta perspectiva que a Pedagogia Crítica deve ser interpretada, isto é, como sendo a base de desenvolvimento de uma consciência cultural crítica na educação para as línguas/culturas estrangeiras.

O segundo capítulo explora os fundamentos filosóficos da Pedagogia Crítica com base na Teoria Crítica e no Pós-modernismo. No que diz respeito à Teoria Crítica, a dimensão instrumental é rejeitada a favor de uma racionalidade mais crítica/in- 
tersubjectiva no processo comunicativo. A análise da comunicação ocupa uma posição central, com particular atenção à massificação da cultura, à "indústria cultural" e às ligações com a consciência cultural crítica. O Pós-modernismo é aqui analisado na perspectiva interessante da redefinição do cânone tradicional. Significativas construções pós-modernas são aqui examinadas: "diferendo", "desconstrução", "simulação", "tecnologias de poder" e "solidariedades". A identidade cultural, a diferença e o conceito de cidadania tornam-se aspectos-chave para se estabelecerem laços entre o pós-modernismo e a consciência cultural crítica. Teoria Crítica e Pós-modernismo desempenham um papel importante na formulação da Pedagogia Crítica; a sociedade é complexa e estratificada e são necessárias novas abordagens na aproximação à sua heterogeneidade.

O terceiro capítulo foi construído sobre as considerações teóricas expressas, de uma forma brilhante, anteriormente. A autora encoraja o leitor a analisar a dimensão crítica do ensino/aprendizagem de culturas estrangeiras, que deveria constituir o âmago do ensino/aprendizagem de línguas estrangeiras. O capítulo inicia-se com a sugestão de uma série de princípios para uma abordagem crítica às culturas estrangeiras. A noção do "Comunicador Intercultural" é discutida em termos de Identidade Cultural, uma realização complexa de uma identidade multidimensional construída a partir das identidades local, nacional e global; a descoberta de uma nova língua e cultura(s) junta um novo estrato ao conceito de identidade, ou seja, a constituição do chamado "terceiro espaço". Particularmente reveladora é a revisão da dimensão crítica nos modelos de Competência de Comunicação Intercultural que se segue, na qual não se examinam apenas contribuições individuais, tais como os mode- los propostos por Brislin/Yoshida, Bennett, Seelye, Damen, Robinson, Kramsch, Byram e Pennycook, que são definidos claramente, mas também documentos de referência tais como o Common European Framework do Conselho da Europa e os Standards for Foreign Language Learning nos Estados Unidos. Finalmente, a autora examina a dimensão política da Educação para Línguas/Culturas Estrangeiras acentuando as suas contribuições para a política cultural e para a educação para a cidadania. Todo o capítulo constitui, portanto, um estudo rigoroso dos "princípios, processos e objectivos que devem levar à realização de uma abordagem crítica no ensino/aprendizagem de culturas estrangeiras" (167-168).

O quarto capítulo é um momento de viragem na medida em que se estabelece a ligação entre a Pedagogia Crítica, a Consciência Cultural Crítica e a Educação para as Línguas/Culturas Estrangeiras numa perspectiva prática. Baseia-se no relatório de uma parte de um estudo referente ao ensino de Inglês como língua estrangeira no ensino secundário em Portugal em que se examina as descrições que os professores fazem das suas práticas no que respeita à promoção de uma consciência cultural crítica. Este estudo é aqui contextualizado do ponto de vista nacional e educativo. A metodologia seguida é uma combinação de questionários, entrevistas de grupos e individuais. São discutidos em pormenor assuntos importantes e, assim, o estudo dá-nos perspectivas interessantes sobre: (a) o ensino crítico de cultura nas aulas de língua estrangeira; (b) a definição de uma abordagem crítica às culturas estrangeiras; e (c) a educação de cidadãos críticos. São daqui retiradas conclusões interessantes sobre o estatuto da consciência cultural crítica nas aulas de Inglês como língua estrangeira em Portugal tais como a vontade de os professores incluirem conteúdos cul- 
turais nas suas aulas de língua, de incorporar uma abordagem crítica, de promover empatia através de análises comparativas/ contrastivas e de promover a educação para a cidadania. A autora conclui que, apesar disso, os professores portugueses ainda não conseguiram "cumprir o seu papel de intelectuais transformadores" (204) porque não estão ainda empenhados na transformação da sociedade uma vez que o seu ensino não atinge a fase da acção. A prática dos professores portugueses confina-se dentro da sala de aula; a educação para as línguas/culturas estrangeiras em Portugal não estabelece a ligação com a comunidade nacional ou internacional, nem com instituições ou pessoas, estrangeiros ou nacionais.

Estudos semelhantes realizados em Espanha sugerem que os professores de línguas estrangeiras desejam também incorporar a componente cultural nas aulas de língua estrangeira, embora não saibam exactamente como o fazer devido, entre outros factores, a uma manifesta falta de formação nesta área nos programas de formação de professores. Os professores espanhóis parecem privilegiar a educação para a cidadania democrática e estão muito conscientes quer da sua cidadania espanhola, quer europeia. Em Espanha, o papel do professor é ainda visto como o de um facilitador e o de um informador e não tanto como o de um intelectual transformador. Tal como os seus colegas portugueses, os educadores espanhóis parecem subvalorizar o seu poder de intervenção na sociedade.

O livro termina com um capítulo conclusivo no qual se estruturam os princípios fundamentais e os dados apresentados nos capítulos anteriores numa visão da preparação de cidadãos e educadores críticos para um mundo intercultural muito relevante para aqueles que estão abertos para aceitar um papel preponderante da Edu- cação para as Línguas e Culturas Estrangeiras na esfera da política (inter)cultural e da educação para a cidadania. A autora, que se mostra claramente a favor de uma abordagem de perspectiva múltipla enquadrada na educação para os direitos humanos e na educação para a cidadania democrática, faz aqui a sua contribuição mais notável com a proposta de um modelo interdisciplinar para o ensino/aprendizagem das culturas estrangeiras no qual a Comunicação Intercultural, os Estudos Culturais e a Pedagogia Crítica interagem em contínuo.O zelo excessivo da autora em promover profissionais críticos e transformadores pode, por vezes, dar a impressão que não há uma prática corrente que seja válida ou digna de ser mantida. A sua ênfase na necessidade de desconstruir parece reclamar, do mesmo modo, mudanças radicais em vez de mudanças graduais. Deve ter-se em conta que os educadores acham difícil realizar a sua missão transformadora porque trabalham para sistemas políticos e educativos específicos que lhes exigem, quer queiram quer não, perpetuar, até certo ponto, o status quo. Para além do mais, existem outros aspectos impeditivos, tais como o material escolar e o ambiente profissional (exames nacionais, os directores das escolas, os colegas e as expectativas dos pais e dos alunos...). As mudanças são desejáveis e inevitáveis, embora a velocidade da mudança não dependa, na minha opinião, tanto dos educadores como autora parece sugerir.

A densidade dos primeiros dois capítulos poderia ter sido parcialmente evitada porque alguns dos aspectos-chave aparecem e são explorados em ambos. De igual modo, o terceiro capítulo teria beneficiado com uma discussão mais alargada dos diversos modelos para a Competência de Comunicação Intercultural. O quarto capítulo concentra-se em alguns aspectos que poderiam constituir um estudo mais amplo; teria sido 
também interessante ter acesso à versão integral do estudo com os professores portugueses sobre a consciência cultural crítica.

Contudo, do meu ponto de vista, Critical Citizens for an Intercultural World, constitui um exemplo de um trabalho bem tecido, que ajuda o leitor a considerar a educação em geral, e a educação para as línguas e culturas estrangeiras em particular, sob uma nova luz, a do indivíduo/profissional transformador, que a autora adopta de Giroux. Sem dúvida que nos faz tornar mais conscientes do significado multidimensional da palavra "crítica" e das atitudes pró-activas e transformadoras que im- plica. Embora o enfoque no ensino/aprendizagem de língua estrangeira possa parecer, de algum modo, indirecto nos primeiros dois capítulos, os últimos três capítulos serão obviamente muito relevantes para os educadores desta área. A ligação valiosa entre Educação para as Línguas e Culturas Estrangeiras e Consciência Cultural Crítica e o esquema utilizado para a sua representação explora novos caminhos que deverão ser adoptados pelos actuais e futuros educadores em línguas e culturas estrangeiras. Este livro deve ser, sem dúvida, integrado na sua lista de leituras.

Maria del Carmen Méndez García

\section{Ronald Barnett, Beyond All Reason: Living with Ideology in the University. Buckingham: The Society for Research into Higher Education \& Open University Press, 2003, 256 pp.}

Nesta obra, Ronald Barnett avança o seu exame crítico do ensino superior para o qual nos tem vindo a preparar nas suas obras anteriores, nomeadamente, Higher Education: A Critical Business (1997), na qual já nos sensibilizava para a importância da realização do espírito crítico em ligação com a exploração do mundo que nos rodeia: "critique as external reflection [...] - the capacity to become an other, to inhabit, if only briefly, a cognitive perspective that is unfamiliar” (p. 19). Já nesta obra advogava que o ensino superior não deve limitar-se ao desenvolvimento cognitivo mas deve ser também eminentemente experiencial, mas... com intenção interventiva. É neste "mas...” que, na minha leitura, se centra este novo trabalho de Barnett quando procede à crítica do novo modelo de universidade, a "universidade empresarial" (the entrepreneurial university). Embora o autor baseie a sua análise no sistema universitário britânico, o seu raciocínio aplica-se, de uma forma muito perti- nente, a outros contextos, nomeadamente ao português. Barnett parte do facto de as universidades estarem em mudança e de esta ser irreversível, analisa o sistema e oferece caminhos. Esta leitura é fundamental para os gestores de instituições de ensino superior e também imprescindível para o seu corpo docente, uma vez que lhes oferece uma visão crítica dos contextos em que se inserem os seus actos. Num processo de globalização das economias e dos mercados de trabalho, as universidades, faculdades e departamentos vêem ameaçados os seus modelos, no general decorrentes de ideais iluministas, e têm duas reacções extremas: ou se fecham em si mesmos, perdendo a sua relevância, ou se abrem demasiado e perdem a sua essência e, mais ainda, o controlo de si próprios. Podem ainda tornar-se "universidades virtuais", actuando no ciber-espaço, e podendo atingir aquilo que a sua imaginação lhe permitir. Barnett centra assim o seu argumento na evocada "perda da Razão", ou 
seja, a perda do ideal iluminista, na universidade do século XXI enfocando esta discussão nas alegadas perdas de Ideologia e de valores e contextualizando-a na chamada "sociedade de conhecimento". O conhecimento já não se confina aos limites físicos da universidade e esta manipula cada vez mais o conhecimento na sociedade e, ao mesmo tempo, deixa-se manipular pelos interesses da sociedade, para daí retirar benefícios económicos e se deixar enredar nos jogos de poder, tanto no plano institucional como individual. Numa sociedade de "supercomplexidade", os critérios não são, pois, muito fixos e evidentes e, para além do mais, não tem havido uma reflexão sistemática ("reflexão metacrítica", como lhe chamava o autor na sua obra anterior referida acima) que estipulasse princípios e valores básicos e que assegurasse uma visão coerente e articulada das suas funções.

Não existe, pois, uma Razão unificante mas múltiplas razões. De acordo com o autor, não há já uma "uni-versidade" mas uma "multi-versidade". No entanto, uma sociedade, sobretudo um mercado, muito forte vai fragilizando a Universidade que vai cedendo aos desejos do consumidor. $\mathrm{O}$ autor identifica diversas formas de complexidade com as quais a Universidade se debate como, por exemplo, entre sistemas formais e informais, entre sistemas e conceitos, entre relações de espaço e de tempo, entre identidades institucionais e pessoais. Intencionalmente ou não, as universidades têm vindo a integrar-se em redes, podendo estas ser processuais (por via electrónica) ou substantivas (por consequência da globalização económica), e têm vindo a incorrer numa crise de identidade tanto no plano institucional como pessoal (quais são os limites/horizontes das funções do académico hoje? - é impossível aqui deixar de pensar no recente caso do Doutor Kelly em Inglaterra). Como refere o autor, estas questões ultrapassam o limite das epistemologias para se situarem no âmbito da ontologia. Qual a relação que a Universidade estabelece entre a sua vocação global e a sua missão local? $\mathrm{O}$ autor disseca criticamente os meandros da gestão universitária, colocando em foco as estruturas sobre as quais assentam as rotinas da vida universitária. No entanto, nunca desvaloriza a energia positiva que, mesmo de forma utópica, pode emergir dessa atitude crítica e vai assinalando as oportunidades que esta nova sociedade das redes de conhecimento pode trazer para o desenvolvimento da Universidade.

De forma muito organizada, o autor vai identificando, um a um, os desafios com que a Universidade se confronta - internos/externos; individuais/colectivos; co nhecimentos disciplinares/interdisciplinares/práticos; instrumentais/hermenêuticos; de gestão/profissionais - bem como as pressões que ela sofre do Estado. Discorre então sobre as implicações para o ethos da Universidade do facto de surgirem de dentro dela própria as teorias sobre o "fim da ideologia”, que levam ao esvaziamento da sua identidade e a uma insegurança na sua ética. Deste modo, vai cedendo aos desejos do consumidor e mesmo interiorizando-os, o que, no entender do autor, será desastroso. $\mathrm{O}$ autor vai construindo a sua tese na rejeição da inexistência de ideologias na Universidade e do pressuposto de que a neutralidade é a base da Razão e do Progresso. Segundo o autor, qualquer ideologia constitui uma leitura do mundo e pressupõe uma Razão contaminada pelos interesses dos que a professam; sendo a ideologia uma fantasia colectiva, o estruturar de uma identidade colectiva, é portanto mais de natureza ontológica do que epistemológica. Os professores não defendem a sua ideologia através da argumentação racional mas através de um "commitment-in-being”, isto é, do seu ser colec- 
tivo e, em consequência, da imagem que passam de si próprios. A ideologia é assim a estruturação de uma verdade colectiva. E, dado que na Universidade, acredita o autor, as ideologias são, pelo menos até certo ponto, auto-impostas, o "ideal" pode servir de critério crítico para re-orientar as práticas académicas. E, assim, o autor vai construir a sua tese com base na divisão entre ideologias "perniciosas" e ideologias "virtuosas", sendo estas últimas as "idealogias" porque assentam em ideais, que podem constituir-se em princípios e valores. Mas estes ideais devem surgir de dentro da universidade e não serem impostos pelo mercado, não se divorciando, contudo, das necessidades da sociedade. O "empresarialismo" (entrepreneurialism) é uma ideologia que se constituiu, de forma perniciosa, fora da Universidade e que esta tem vindo a interiorizar, mas que pode vir a transformar numa "idealogia" (ideologia virtuosa) se cultivar o espírito empreendedor e aberto que esta ideologia também alberga. A voracidade do empresarialismo, enquanto ideologia perniciosa, altera o ritmo normal da universidade e impede o espaço e o tempo para a reflexão crítica, contudo, os departamentos estrangulados financeiramente e os académicos com contratos precários são forçados a correr atrás da onda. A lógica de mercado vai, assim, ficando ontologicamente difusa na dinâmica da Universidade e o papel desta como forum de crítica vai-se esbatendo. No entanto, refere o autor, o entrepreneurialism (aqui entendido mais como "espírito empreendedor") pode constituir um desafio positivo para a Universidade, porque desafia as suas epistemologias, os seus processos comunicativos e as suas identidades centenárias (74).

Para os académicos resistentes, este conceito vai obviamente ameaçá-los com o fim das suas fronteiras, do seu discurso impreciso e da sua ambiguidade comunicativa.
O autor analisa então a competição entre universidades, imposta pelo estado, segundo critérios que não são definidos pela Universidade e que coloca universidades contra universidades, e distingue a avaliação feita pelos participantes directos (necessary others) e pelos indirectos (non-necessary others) na vida académica. Por outro lado, o autor reconhece que os primeiros (professores e estudantes) também podem contribuir para a corrupção dos actos académicos e que a competição pode gerar espaços de aperfeiçoamento (epistemológico, comunicativo e ontológico), sobretudo se se orientar para o autodesenvolvimento de cada instituição.

O conceito de qualidade é também aqui analisado e defende-se que não é um conceito neutro, dado que a estipulação de critérios vai corresponder a uma ideologia (perniciosa ou virtuosa). No que se refere à "Comunidade Académica", o autor considera que é neste elemento que se torna mais forte a noção de que o "fim da ideologia” é, na realidade, uma ideologia que será perniciosa se corresponder a um excessivo individualismo dos académicos, sendo que esta ideologia se vai construindo de forma subreptícia. Por este motivo, só uma liderança forte pode transformá-la numa "ideologia virtuosa", desde que valorize mais os objectivos processuais do que os operacionais, o entendimento colectivo (dos académicos enquanto indivíduos) do que os interesses corporativos. Mas deverá estar assente em valores negociados e reformuláveis. A vida académica, em tempo de uma "modernidade fluida" (Bauman é aqui citado) oferece situações em que o pessoal, o experiencial e o transaccional adquirem maior significado. A fragmentação do conhecimento reflecte-se nos planos epistemológico, ontológico e organizacional e, em consequência, na ética universitária, através da proliferação de valores (128) e da desestabilização das 
ideologias. É neste sentido que as "idealogias" podem salvar o projecto da Universidade, porque, sendo "ideologias utópicas”, jogam com razões (e não se fundamentam no conceito da Razão una e inflexível) e, ao mesmo tempo, são projectos práticos onde se realizam os ideais da Universidade. Por fim, o autor examina a dicotomia entre investigação e ensino na vida universitária e descreve-as como duas ideologias em competição, com a recente preponderância da primeira. Este facto tem alterado ontologicamente a vida universitária porque mudou o enfoque do "ensino" para a "aprendizagem".

Esta obra acaba por oferecer um modelo de Universidade onde coabitam vários tipos de razão, várias epistemologias e vários tipos de produção de conhecimento que se distribui pela sociedade, em suma, uma Universidade mais razoável, generosa, inclusiva, interactiva, empreendedora, enfim, mais enérgica e interveniente. Para este efeito, o autor realça a necessidade de quatro dimensões para o discurso académico - instrumental, dialógica, ontológica e poética - que se resumem numa "cultura de amizade crítica" baseada na "incerteza ontológica" e que colocam a universidade num estado contínuo de complexidade, “complexity-in-being" (pp. 174-178). No Anexo 1, pode consultar-se um interessante glossário dos termos utilizados ao longo da obra. Para além das obras anteriores de Barnett, têm sido publicados recentemente outros trabalhos que constituem um bom complemento para esta leitura, dos quais se salientam, todos publicados em 2001, Melanie Walker (org.), Reconstructing Professionalism in University Teaching: Teachers and Learners in Action, saído na mesma editora e que apresenta também exemplos práticos, Di Napoli, Polezzi \& King (orgs.), Fuzzy Boundaries? Reflections on Modern Languages and the Humanities, editado pelo Centre for Information on Language Teaching and Research, que se concentra na remodelação do estudo das línguas e culturas estrangeiras no ensino superior, e ainda Stoer, Cortesão \& Correia (orgs.), Transnacionalização da Educação. Da crise da Educação à "educação" da crise, publicado pelas Edições Afrontamento como parte da série A sociedade portuguesa perante os desafios da globalização.

Manuela Guilherme

\section{José Machado Pais, Ganchos, tachos e biscates. Jovens, trabalho e futuro. Porto: Ambar, 2001, 437 pp.}

"Ganchos, tachos e biscates. Jovens, trabalho e futuro" é mais um trabalho do sociólogo José Machado Pais, sem dúvida a maior referência no âmbito dos estudos sobre culturas juvenis em Portugal. A obra é uma deambulação por percursos, trajectórias de vida, que o autor designa como encruzilhadas labirínticas, trajectórias em yô-yô, e que nos remetem para a questão de fundo - a precariedade laboral vivida por muitos jovens.
José Machado Pais efectuou uma série de entrevistas com diversos jovens, todos com histórias de vida diferentes e complexas, cujo principal objectivo é conhecer as dificuldades de emprego e sobrevivência desses jovens. Para além das suas diferenças (de sexo, idade, origem, classe, nível educacional, etc.) somos levados a concluir que a precariedade e instabilidade pode atingir todos os jovens no mundo da economia global em que hoje vivemos. 
Nas histórias relatadas, vemos que determinados trabalhos não são difíceis de arranjar, mas mais complicado é arranjar um emprego, no sentido de se fazer aquilo que se gostaria ou que está à medida das qualificações adquiridas. Deste modo, os jovens vão fazendo o que vai surgindo, consoante as suas necessidades, o seu enquadramento familiar ou os seus apelos de consumo. Ninó vai fazendo biscates para ajudar os pais, mas também porque queria juntar dinheiro para umas férias no Algarve. Teodoro começou a trabalhar para pagar a universidade privada, mas grande parte do seu salário é para jantar e sair com os amigos.

Os jovens vão trabalhando em paralelo com outras actividades. Muitos são estudantes, outros não. São toxicodependentes, são disc-jokeys. José Machado Pais retomou as entrevistas mais que uma vez, retratando momentos significativos das trajectórias pessoais dos entrevistados. O percurso profissional anda lado a lado com outros aspectos da vida dos jovens, como a família, a escola e os estudos, os amigos.

O autor pretende adoptar uma epistemologia interpretativa, considerando o discurso do entrevistado como um acto de representação, pelo que a entrevista terá de ser descortinada pelo próprio leitor através de uma leitura aberta e polissémica. Daí, a opção de incluir as entrevistas quase na integra, bem como as notas pessoais do diário de campo do investigador.

A universidade e a relação dos jovens com a escola não são os temas desta obra, mas são sem dúvida factores decisivos no acesso dos jovens ao mercado de trabalho. Em algumas das histórias apresentadas, podemos fazer leituras sobre a relação dos jovens com o ensino. Por exemplo, os biscates e os ganchos podem surgir porque os jovens não se inserem na escola. Esta não adaptação pode surgir por várias razões: por má integração na turma, por "calhar" numa turma só de repetentes, por ter professores que não conseguem "ter mão" nos alunos, por os professores e órgãos directivos afirmarem ao aluno e aos seus pais que ele não faz nada na escola. Também a escola pode ser geradora de estigmas. Pior, pode levar alguns jovens a acreditar no estigma. Assim foi com M7, jovem recluso, ou com Francisco, arrumador de carros, que cedo abandonaram os estudos. Se a escola não é um espaço integrador, pode levar a procurar outras vias, outros caminhos, de integração ou exclusão, como por exemplo a delinquência. Para Inês, estudante de antropologia, a universidade é um espaço de solidão. Isso porque deixou algumas cadeiras para trás e todos os seus amigos já acabaram, casaram. Entra na universidade para ir às aulas e sai mal estas terminam.

No caso de Teodoro, por exemplo, a universidade é mais do que ter aulas. Participar na associação de estudantes , ser presidente da mesma, funciona como um treino para a sua ambicionada carreira política. Para si, isso é particularmente importante e considera que se calhar aprendeu mais do que os colegas que vão regularmente às aulas. Mas, neste caso, estamos diante de um jovem que tem projectos futuros orientados, sabe o que quer fazer.

O mesmo não se verifica em relação à universidade e ao curso. $\mathrm{O}$ canudo como garantia futura de fazer o que se estudou, é uma miragem. Uma angústia, uma incerteza.

Ninó é finalista do curso de agronomia e ao longo de todo o curso tem tido uma série de trabalhos esporádicos e indiferenciados. Do telemarketing a promoções de produtos no hipermercado. Não se importa com o que faz, de estar sempre a saltitar de trabalho em trabalho. Mas a opinião já é diferente se continuar a ter estes trabalhos quando acabar o curso. 
O "acabar o curso" parece ser para muitos jovens estudantes o momento decisivo das suas vidas, como se nessa altura tudo se fosse resolver. Inês concilia ser estudante universitária com ser prostituta. Pensa deixar a prostituição quando acabar o curso.

Mas acabar o curso enquanto projecto futuro, é um tempo próximo mas distante, repleto de incertezas, dúvidas e angústias, e uma altura em que as coisas serão ou não diferentes. Inês parece inquieta à espera do futuro, como se ele entrasse por uma porta e lhe mostrasse as novas coisas da sua vida.

E assim chegamos à ideia central do autor, a de que muitos jovens vivem a universidade e o futuro como um compasso de espera e que a escola é "um parque de estacionamento de potenciais desempregados" (p. 45). Como se os jovens fossem "cheques pré-datados, sem valor no presente, e possivelmente, sem valor no futuro" (p.415). Deste modo, muitos jovens, enquanto estudam, embarcam em tachos, ganchos e biscates, tentando desenrascar-se no presente, para chegarem a um futuro. Esse futuro ninguém sabe como é, porque as suas trajectórias em yô-yô são labirínticas, de continuidades e de rupturas.

$\mathrm{Na}$ escola, alerta o autor, "o futuro não se deve pensar como algo já feito. O futuro vai-se fazendo, preferencialmente de forma participada, envolvendo jovens. Mas o que ainda predomina na escola é uma cultura prescritiva: de planos e matérias de estudo, de normas disciplinares, de provas globais (estandardizadas), de práticas pedagógicas que se inscrevem numa filosofia de "produção em série" - o que se justifica pela massificação de ensino, sujeito, cada vez mais, a economias de escala" (p. 414).

Em suma, José Machado Pais oferece várias leituras possíveis sobre a vivência laboral de muitos jovens. Demonstra que não podemos analisar a realidade sem ter em conta a sua complexidade e que a juventude não pode ser considerada como um todo homogéneo e coeso. Por isso sugere uma "sociologia pós-linear".

"Ganchos, tachos e biscates" é um exemplo de um exercício notável de transdisciplinaridade. José Machado Pais deambula pela sociologia, etnografia, mitologia, simbolismo, psicanálise, matemática, filosofia, linguística ou a semiologia, num registo literário, por vezes, até poético. $\mathrm{O}$ autor é um contador de histórias, que rejeita o discurso "sociologuês". Um dos grandes trunfos deste livro é poder ser lido e compreendido por qualquer leitor mesmo sem formação na área de ciências sociais.

Porém, não parece haver o mesmo grau de tratamento em todas as histórias. Algumas revelam-nos pouco. Talvez por o autor ter uma linguagem tão cativante e revelar factos biográficos dos entrevistados, ficamos com a sensação de que às vezes falta qualquer coisa, que algo ficou por contar. Por exemplo, em alguns episódios sabemos porque determinado jovem escolheu determinado caminho. Noutros, apenas sabemos o que fez, e não porque o fez. O registo é etnográfico, mas não plenamente. Por vezes, surge a sensação de que a vertente social retratada está próxima da ficção. Pelas analogias que efectua, a fronteira do que é social e do que é ficcionado pode ser frágil. É uma linguagem próxima porque é descritiva, literária, para ler como se fosse um romance. Mas em certos passos ficamos na dúvida sobre se a realidade descrita não é demasiado romanceada.

Uma das grandes contribuições da obra é permitir leituras e pistas para pensarmos várias questões mencionadas: a discriminação étnica e racial no trabalho; a questão do desvio, da marginalidade e da toxicodependência; a inserção de jovens reclusos na sociedade, após cumprimento da pena; o trabalho infantil ou a prostituição. 
Contudo, ir por partes para chegar ao todo, analisar fragmentos da realidade complexa para possíveis leituras e conclusões temporárias é analisar apenas a superfície. $\mathrm{Ou}$ seja, questões mencionadas, como a exploração do trabalho infantil, a escola como produtora e reprodutora de estigmas, a universidade enquanto parque de estacionamento de potenciais desempregados, entre outras, são apenas enunciadas, sem que o autor verdadeiramente se comprometa no diagnóstico social ou no seu significado político. Nessa medida, seria talvez aconselhável dar agora continuidade a esta abordagem através de uma análise mais aprofundada, que nos permitisse perceber algumas das causas estruturais dos problemas com que se debatem os jovens de hoje.

Inês Sacchetti

\section{Jürgen Hoffmann (org.), The Solidarity Dilemma: Globalisation, Europea- nisation and the Trade Unions. Brussels: European Trade Union Institute, 2002, 215 pp.}

Organizado por Jürgen Hoffmann, conceituado especialista em questões laborais e sindicais no quadro europeu e global, o presente livro é o resultado de uma conferência realizada em Março de 2001 pelo Instituto Sindical Europeu (ISE). A maioria dos textos reunidos em The Solidarity Dilemma são versões revistas das contribuições para essa conferência, consagrada à análise dos desafios colocados aos sindicatos num contexto de europeização e de globalização.

A ideia recorrente de que os sindicatos se encontram, por um lado, fracturados pela assunção de um conjunto de políticas nacionais diversificadas (dos pontos de vista organizacional, económico, cultural) e de que, por outro lado, são normalmente vistos como vítimas da globalização é referida logo na introdução da obra. Porém, o grosso dos artigos admite que os sindicatos têm um potencial que pode ser explorado, uma vez que, quer no plano nacional, quer nos planos europeu e global, eles estão confrontados com tarefas semelhantes: regular a diversidade de tal modo que, perante o capital e as instituições europeias e internacionais quase-estatais, as formas de representação baseadas na solidariedade sejam possíveis, sem negar as diferenças nas condições de trabalho e de vida (pp. 3-4). Sugere-se, assim, a tese de que os desafios propiciados pela europeização e pela globalização são semelhantes aos vivenciados no âmbito dos Estados nacionais. Nesse sentido, requere-se, em ambos os níveis (global e regional), o envolvimento dos sindicatos num novo processo de aprendizagem, caracterizado acima de tudo pela necessidade de incorporar uma maior complexidade nas suas políticas organizacionais.

Na maioria dos capítulos do livro, foi grande a preocupação em discutir o conceito de globalização, quase sempre enfatizando o seu carácter ambíguo e contraditório. Digamos que uma lógica binária associada à globalização (e à regionalização) acabou por estar presente em vários dos contributos. Por exemplo, Pierre Defraigne (capítulo 2) confronta a globalização da eficiência com a globalização da igualdade e posiciona o modelo europeu perante o mito e a realidade, concluindo pela necessidade de uma "globalização politicamente regulada" tendo por base a União Europeia (pp. 19-27). Por sua vez, Mario Telò (capítulo 3) analisa as complexidades associadas ao "novo regionalismo" (pp. 34-36), discutindo também o papel da UE enquan- 
to espaço intermédio entre a globalização e a existência de novos agrupamentos regionais. Ludger Pries (capítulo 4), que se centra sobretudo nos tipos e estratégias da “empresa internacional”, para além de fornecer várias definições de globalização, reporta-se igualmente quer aos seus defensores, quer aos seus críticos (pp. 43-48). De igual modo, e de forma ainda mais demorada (pp. 122-131), Jürgen Hoffmann (capítulo 7) recupera o debate entre os defensores das teses da "globalização forte" e da "globalização fraca", posicionando-se criticamente face a ambas.

No conjunto, penso que uma reflexão mais apurada sobre a noção de solidariedade e sobre as hesitações que ela suscita no movimento sindical (afinal, o livro intitula-se $O$ dilema da solidariedade) acabou por estar um pouco ausente na obra. Foi pena, por exemplo, que na abordagem histórica do processo de construção do sindicalismo europeu Andrea Ciampani (capítulo 5) não tenha incorporado uma referência fundamentada às ambições de emancipação e solidariedade operária, tendo em conta os objectivos internacionalistas pelos quais o internacionalismo operário se guiou na sua origem. Mas ainda que nem sempre façam referência explícita à noção de solidariedade, vários dos contributos deste livro propõem, em especial no quadro da UE, o que eu designaria por caminhos solidários alternativos, nos quais podem vislumbrar-se compromissos com o valor da solidariedade, afinal um requisito permanente dos discursos e estratégias dos sindicatos. É o que faz Pierre Defraigne, ao delinear como missão para a UE o reconhecimento da legitimidade de um conjunto de pontos de vista (não necessariamente coincidentes com os seus) no domínio dos direitos humanos, laborais e ambientais. Parece-me sugestiva uma das interrogações do autor a este respeito: "Não terá a Europa ido longe de mais com a sua visão de individualismo, negligenciando o facto de que os seres humanos fazem parte de várias comunidades, da família à municipalidade e aos grupos políticos, sindicais e religiosos?" (pp. 25-26). Ao apelarem a uma missão multicultural para a UE, considero que estas e outras propostas deste autor funcionam igualmente como referencial importante para a actuação das organizações sindicais. Com efeito, a hipótese sustentada por Mario Telò - segundo a qual o novo regionalismo (que é mais profundo, político, conduzido de "baixo para cima", está longe de ser só económico e é compatível com a integração regional de outras regiões, pp. 36-37; 41) constitui o melhor enquadramento para orientar os interesses sindicais para uma forma mais justa e regulada de globalização (p. 41) -, vai nesse sentido e implica um forte apoio do movimento sindical: "sem o forte e consciente apoio do movimento sindical, as instituições europeias nunca serão capazes de reivindicar um novo multilateralismo que incorpore o respeito por três componentes: (i) abertura à sociedade civil, (ii) defesa dos direitos humanos e sociais, e (iii) uma contribuição mais simétrica por parte de múltiplos actores, incluindo entidades regionais" (pp. 41-42).

Porém, os dois capítulos que, a meu ver, melhor promovem uma discussão equilibrada e empiricamente fundamentada dos desafios e respostas do movimento sindical num quadro de globalização e, sobretudo, de europeização, sem perder de vista a noção de solidariedade, são os de Jon Erik Dølvik (capítulo 6) e de Jürgen Hoffmann (capítulo 7). A contribuição de Dølvik apoia-se na tese de que, na luta pela justiça social e pela regulação do capitalismo contemporâneo, a integração sindical regional não constitui uma alternativa, mas um "intermediário crucial entre os níveis nacional e global” (pp. 83-84). Nesse sentido, diante das dinâmicas e constrangi- 
mentos da globalização e das ambiguidades da própria integração europeia, o autor defende a edificação de "estratégias sindicais transnacionais pró-activas” (p. 100) como condição para que o sindicalismo conserve o seu papel e aumente a sua influência nas emergentes estruturas regionais e globais de governação da economia mundial. Particularmente interessante é a forma como, na terceira secção do capítulo, o autor se reporta ao desenvolvimento do sindicalismo numa perspectiva transnacional. $\mathrm{Na}$ sequência de uma exposição bem esquematizada dos níveis e fontes de poder do sindicalismo, Dølvik reforça a ideia (de resto partilhada por outras contribuições deste livro) de que as políticas sindicais permanecem essencialmente de base nacional, ao passo que as actividades internacionais se caracterizam pelo trabalho de solidariedade sindical, norteado frequentemente por considerações ideológicas, actividades diplomáticas e tributos ritualistas em congressos e celebrações do Primeiro de Maio (p. 107). Ainda assim, são mencionados alguns exemplos que têm contribuído para reforçar o papel transnacional do sindicalismo: os Conselhos de Empresa Europeus; a negociação de acordos-quadro europeus; o reforço das estruturas sindicais europeias; o debate sobre os padrões laborais mínimos, tendo por referência a Organização Internacional do Trabalho; o "Debate do Milénio", promovido pela Confederação Internacional dos Sindicatos Livres; ou ainda o "Cibersindicalismo", que permite criar redes de informação e mobilização transnacionais entre trabalhadores e sindicatos.

O principal obstáculo à promoção de interesses laborais à escala global assinalado por Dølvik reside na "ausência de contrapartes públicas coerentes” (p. 109) susceptíveis de promoverem um diálogo social de modo amplo. Daí que, citando Colin Crouch e Richard Hyman, a principal lição que o autor colhe do cenário europeu seja a seguinte: a interacção com os interlocutores públicos dotados de autoridade política para regular os mercados de bens e de trabalho é um pré-requisito fundamental para a construção de estruturas sindicais e de relações laborais viáveis (p. 113). Mas, para isso, é importante também que os sindicatos saibam lidar com o principal desafio que têm pela frente e que consiste em saberem construir estruturas e práticas organizacionais que possam servir de ponte e superar o "hiato entre a filiação no âmbito nacional e as actividades das estruturas sindicais internacionais" (p. 114).

O outro contributo de maior relevância deste livro é o de Jürgen Hoffmann. Tal como Dølvik, entendo que Hoffmann parte também de uma visão algo defensiva a respeito do lugar ocupado pela solidariedade no universo sindical. $\mathrm{Na}$ verdade, este autor começa por observar que o conceito de solidariedade e as pretensões internacionalistas a ele associadas não atingiram o coração das políticas sindicais, votadas que estiveram estas ao "fechamento social" inerente aos mercados de trabalho nacionais em que as práticas sindicais foram edificadas. $\mathrm{O}$ desafio lançado pelo autor no seu texto é, pois, o de ir ao encontro de exemplos e situações que superem esse fechamento social em que os sindicatos e a solidariedade ficaram enredados (p. 120). Nesse sentido, admitindo como inevitável a internacionalização da organização e das políticas sindicais, Hoffmann, recuperando as propostas de Bernhard Ebbinghaus e Jelle Visser, discute criticamente as opções "hierarquia", "mercado" e "rede": o primeiro termo coloca a tónica na criação de uma unidade internacional centralizada e os dois restantes, numa " diversidade regulada” (pp. 132-136; 141-143). O autor parece manifestar maior apetência pelas segunda a terceira opções, 
sobretudo pela amplitude que lhes subjaz e pelo facto de poderem ser moldadas de "baixo para cima". Refere como exemplos, para além do caso dos Conselhos de Empresa Europeus (que Dølvik referira também), a implementação de formas de negociação colectiva de nível europeu, de âmbito multi-sectorial, sectorial, empresarial ou regional. Aliás, a este respeito o último capítulo do livro, da autoria de Emmanuel Mermet, analisa em detalhe os principais contributos da Confederação Europeia de Sindicatos (CES) para a coordenação da negociação colectiva.

Concordo com a ideia avançada por Hoffmann, segundo a qual a solidariedade pode dividir (p. 137), até porque assenta em condições reais contraditórias e não em mitos (p. 143). Penso que este ponto de vista acaba por servir, em parte, de justificação para o título do livro. Afinal, para ser efectiva, a solidariedade sindical tem de libertar-se não só das contradições que sobre ela incidem e que resultam da globalização "má" da economia, mas ao mesmo tempo dos perigos inerentes a uma incorporação dessas próprias contradições no discurso e prática sindicais. Ou seja, as estratégias sindicais, ao irem a reboque das estratégias empresariais para as combaterem de forma reactiva, acabam muitas vezes por reproduzir os seus próprios pre- juízos, lançando nos próprios sindicatos a dúvida quando ao(s) espaço(s) preferenciais onde estimular a solidariedade. Hoffman reconhece, como efeito, que o caminho a percorrer pelo sindicalismo é difícil. Porém, acredita que é viável percorrê-lo, até porque "as crises são sempre uma oportunidade para a mudança". Nesse sentido, a "solidariedade internacional como oportunidade" (p. 143) é desejada e uma europeização das relações laborais bem sucedida é uma condição fundamental para o exercício de uma solidariedade política para além das fronteiras da Europa (p. 141).

No seu todo, este livro constitui um valioso contributo reflexivo, a somar-se a outros que ao longo dos últimos anos vêm sendo editados pelo ISE e que, por regra, têm a UE e o sindicalismo europeu protagonizado pela CES como pano de fundo. Ainda que esteja porventura excessivamente centrado na realidade europeia e nem sempre tenha (como referi) discutido "por dentro" o conceito de solidariedade, este livro aponta, no entanto, um conjunto de pistas de actuação sindical situadas para além dos habituais espaços nacionais de referência. É através delas que somos, afinal, reconduzidos ao dilema da solidariedade.

Hermes Augusto Costa 